\title{
EFFECT OF PRE- and POST-NATAL EXPOSURE TO FLUORIDE ON FLUOROSIS INDICATORS IN OFFSPRING OF RATS
}

Interlandi V, Fontanetti P, Ponce RH, Tirao, G., Rigalli, A , Gallará R, Centeno V.

Cátedra "A" de Química Biológica. Facultad de Odontología, UNC. ㄴaboratorio de Biología Ósea. Facultad de Medicina, UNR.

Controversy exists over the maternal-fetal passage of fluoride $\left(F^{-}\right)$. This work sought to explore different aspects of $\mathrm{F}^{-}$metabolism during pregnancy and lactation in mothers and offspring. The specific aim was to study $\mathrm{F}^{-}$accumulation in bones and teeth and growth morphometric parameters in the offspring of mothers exposed to high levels of $\mathrm{F}^{-}$in drinking water. Pups aged 10-, 15- and 21-day-old from 2 groups of mothers were used: a) controls mothers ( $0.3 \mathrm{mg} / \mathrm{L} \mathrm{F-})$; b) treated mothers $(50 \mathrm{mg} / \mathrm{L} \mathrm{F-)}$. The treatment was performed during the period of pregnancy and lactation. All animals were euthanized and the upper and lower jaw and tibia of mothers were removed for the determination of $\mathrm{F}^{-}$. Incisors diameter, mandibular growth and tibia length were determined on RX digitalized images. Results were analyzed by Student $t$ test. Accumulated $F^{-}$ content was significantly higher in the jaws $(p<0.05)$, incisor $(p<0.01)$ and tibia $(p<0.05)$ of mothers exposed to $\mathrm{F}^{-}$compared to control. In 10- and 15-day-old pups born to treated mothers, $\mathrm{F}^{-}$content in jaws did not differ from the control. However, in 21-day-old pups, accumulated $\mathrm{F}^{-}$was higher $(p<0.05)$. No differences were found in $\mathrm{F}^{-}$content or growth parameters in tibia of the offspring in all studied groups. Lower incisor diameter was lower in 21-day-old pups born to mothers exposed $50 \mathrm{mg} / \mathrm{L} \mathrm{F}^{-}$compared to their controls $(p<0.01)$. The results suggest that $\mathrm{F}^{-}$ accumulation in calcified tissues of the offspring is lower than in maternal tissues. The passage of $\mathrm{F}^{-}$mother-offspring could occur through milk during lactation. Further studies would help to elucidate the mechanism of this process. 